\title{
Prenatal detection of fetal aneuploidies using transcervical cell samples
}

\author{
J Sherlock, A Halder, B Tutschek, J Delhanty, C Rodeck, M Adinolfi
}

Department of

Genetics and

Biometry, The Galton

Laboratory, University

College London,

Wolfson House, 4

Stephenson Way,

London NW1 2HE, UK

J Sherlock

A Halder

B Tutschek

J Delhanty

M Adinolfi

Department of

Obstetrics and

Gynaecology,

University College

Hospital, University

College London,

Chenies Mews,

London, UK

J Sherlock

A Halder

B Tutschek

J Delhanty

C Rodeck

M Adinolfi

Correspondence to:

Dr Sherlock.

Received 17 September 1996 Revised version accepted for publication 25 October 1996

\begin{abstract}
In the course of an investigation aimed at detecting the presence of trophoblastic cells in the endocervical canal of pregnant women between 7 and 17 weeks of gestation, several cases of aneuploidies were observed using a fluorescent in situ hybridisation (FISH) assay. The cases include fetal chromosome 21 and 18 trisomies, triploidy and sex chromosome aneuploidies. The results were confirmed by testing placental tissues obtained after termination of pregnancy (TOP). In two of these cases, clumps of cells with the morphology of trophoblasts were isolated from the transcervical cell (TCC) samples using micromanipulation. FISH and fluorescent polymerase chain reactions (PCR), performed on these clumps, showed them to be exclusively of fetal origin. These results show that prenatal diagnoses of major aneuploidies can be performed by FISH using whole TCC samples, or on isolated clumps of cells by FISH and PCR assays. ( $¥$ Med Genet 1997;34:302-305)
\end{abstract}

Keywords: transcervical cells; FISH; fluorescent PCR; chromosomal aneuploidy detection.

Recent investigations have shown that trophoblastic cells are present in transcervical samples collected from pregnant women between 7 and 17 weeks of gestation. ${ }^{1}$ Molecular analysis of TCCs retrieved by lavage of the endocervical canal have documented the presence of fetal cells as judged by the detection of $\mathrm{Y}$ derived DNA sequences using $\mathrm{FISH}^{2}$ or PCR assays. ${ }^{13}$ $\mathrm{Rh}(\mathrm{D})$ DNA sequences have also been observed in samples obtained from $R h(D)$ negative mothers with $\mathrm{Rh}(\mathrm{D})$ positive fetuses. ${ }^{4}$ Here we report five fetal chromosome disorders detected prenatally in the course of investigations aimed at comparing two methods, lavage and aspiration, for the collection of transcervical samples. ${ }^{5}$ In two cases, clumps of cells were isolated from the whole transcervical samples by micromanipulation under an inverted microscope ${ }^{6}$ and the diagnosis of triploidy and sex chromosome aneuploidy (XYY) confirmed using FISH and PCR on these isolated fetal trophoblastic cells. The isolation of single or clumps of fetal cells free of maternal contaminants offers the opportunity of performing prenatal diagnoses of fetal single gene disorders as well as chromosome aneuploidies.

\section{Materials and methods}

TCC samples, together with maternal peripheral blood, were collected from pregnant women between 7 and 13 weeks' gestation before TOP. A sample of placenta was retrieved after the TOP procedure. TCC cells for FISH were washed in phosphate buffered saline (PBS) before methanol:acetic acid fixation and slide preparation. Standard FISH protocols were performed using probes specific for the centromere of chromosome $18^{2}$, the centromere of chromosome $1,{ }^{7}$ two cosmid contigs specific to chromosome $21,{ }^{8}$ and directly labelled probes specific to chromosomes $\mathrm{X}$ and $\mathrm{Y}^{7}$ In all instances, unless otherwise stated, at least 200 nuclei were analysed in each sample.

In two cases, clumps of cells with the morphology of trophoblasts were removed from the fresh TCC sample using micromanipulation. ${ }^{6}$ These cell clumps were tested by FISH or quantitative fluorescent duplex PCR with primers specific for a polymorphic short tandem repeat (STR) on chromosome $21, \mathrm{D} 21 \mathrm{~S} 11,{ }^{9}{ }^{10}$ and the amelogenin region of the sex chromosomes. ${ }^{11}$

CASE 1

In a 42 year old patient, transcervical chorionic villus sampling (CVS) performed 10 weeks 2 days after the last menstrual period showed trisomy 18. Intrauterine lavage was carried out eight days after the CVS, before TOP. FISH was performed on the TCC sample with a chromosome 18 specific centromeric probe. Three fluorescent signals were observed in 35 of $136(26 \%)$ cells examined, indicating them to be of fetal origin; the remaining cells displayed two signals (maternal origin).

\section{CASE 2}

An intrauterine lavage sample was obtained before TOP from a woman at risk of carrying a fetus with trisomy 21 owing to advanced maternal age. No invasive procedure had previously been performed. FISH was carried out, without knowledge of the karyotype of the fetus, on cells from the TCC sample using two cosmid contigs labelled with different fluorochromes; four of the 500 cells examined $(0.8 \%)$ were found to contain three doublets and hence three copies of chromosome 21 . In our laboratory the erroneous presence of three doublet signals in normal diploid cells is less than 1 in 1000 . The presence of more than three cells with three doublet signals has been found to be statistically significant evidence of trisomy. ${ }^{8}$ Samples of placenta obtained following TOP were subsequently karyotyped, confirming the result of fetal trisomy 21 . 


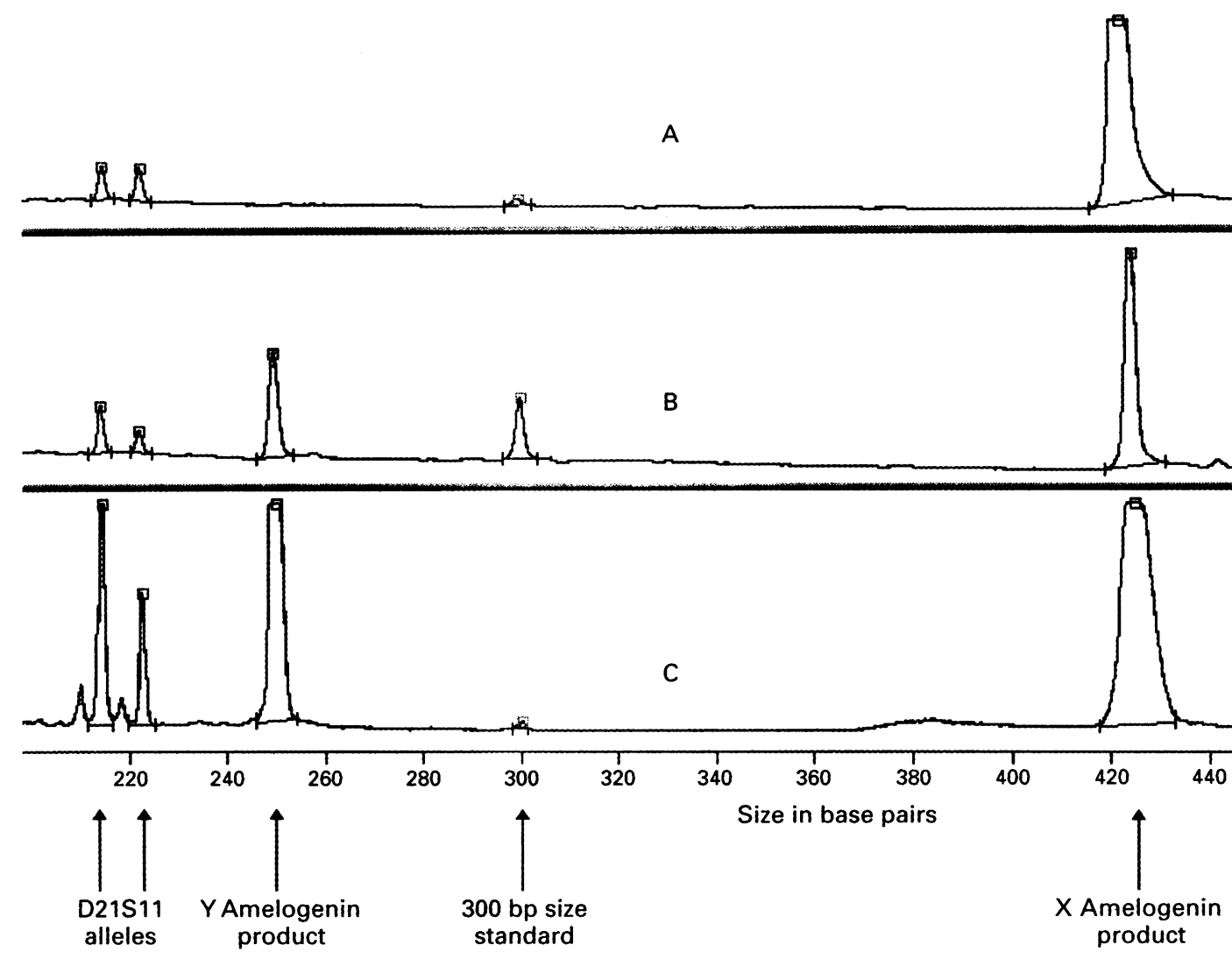

Figure 1 Quantitative multiplex PCR analysis from an $X X Y$ triploid pregnancy. DNA was amplified from maternal blood $(A)$, placenta $(B)$, and a clump of cells isolated from the transcervical mucus aspirate $(C)$. Relative abundance of D21S11 alleles and amelogenin PCR products are compared. The two D21S11 alleles (chromosome 21 marker) with a signal intensity ratio of 2:1 in both the placental and isolated cell clump indicate the presence of three copies of chromosome 21. These results combined with both $X$ and $Y$ specific $P C R$ products coamplified at the amelogenin locus are consistent with the FISH diagnosis of fetal triploidy.

CASE 3

In the course of a study aimed at comparing the results of collecting endocervical cells by aspiration and lavage, a sample of cervical mucus was retrieved by aspiration before obtaining a further sample by lavage from a 24 year old primigravida who sought TOP at 7 weeks of gestation. A maternal peripheral blood sample and placental tissue were also collected after TOP. Using an inverted microscope, small clumps of cells with the morphological characteristics of syncitiotrophoblastic or cytotrophoblastic cellular elements were isolated from the endocervical samples retrieved by aspiration or lavage. Nuclei prepared from these cells, as well as cells present in the TCC samples and from dissociated placental cellular elements, were analysed by dual colour FISH using $\mathrm{X}$ and $\mathrm{Y}$ chromosome specific probes labelled with FITC (green) or rhodamine (red). The results of the FISH tests showed that $6.7 \%$ (seven out of 111 ) nuclei from the aspirated sample and $2.7 \%$ (three out of 111 ) nuclei from the lavage exhibited two green $(\mathrm{XX})$ and one red (Y) signal, thus suggesting that the fetus could have a 47,XXY chromosomal abnormality or triploidy. In control experiments using cultured lymphocytes of female origin, erroneous observations of $47, \mathrm{XXY}$ cells occur at less than $0.02 \%$ (0 nuclei in 4239 examined), thus showing these results to be significant. Further FISH tests with a chromosome 1 derived probe documented the presence of nuclei with three chromosomes 1 in the endocervical samples. The diagnosis of triploidy was then confirmed by FISH analysis of the isolated placental cellular elements. When the isolated cell clumps were tested by FISH using $\mathrm{X}$ and $\mathrm{Y}$ probes, all nuclei in seven clumps isolated from the aspiration sample and four from the lavage sample contained two $\mathrm{X}$ and one $\mathrm{Y}$ signals.

Another isolated cell clump was tested by quantitative multiplex fluorescent PCR with a polymorphic STR marker on chromosome 21 (D21S11) coamplified with primers specific for the amelogenin region of the sex chromosomes. This assay displayed the same pattern as tested placental DNA, two STR allele sizes with a quantitative ratio of $2: 1$ owing to the presence of three chromosomes 21 and $\mathrm{X}$ and $Y$ specific PCR products. These results are consistent with the cells being of fetal origin and with the FISH diagnosis of triploidy (fig 1).

CASE 4

In the fourth case a twin pregnancy with two distinct placentae was detected using ultrasound before TOP at 11 weeks' gestation. TCC, placenta, and fetal tissue samples were carefully collected along with peripheral 
Table 1 Cell populations in fetal samples

\begin{tabular}{llllll}
\hline & \multicolumn{2}{l}{ Twin $A$} & & \multicolumn{2}{l}{ Twin $B$} \\
\cline { 2 - 3 } \cline { 5 - 6 } Sample & $\% X X Y$ & $\% X Y Y$ & & $\% X X Y$ & $\% X Y Y$ \\
\hline Placenta (site A) & 93 & 7 & & 20 & 80 \\
Placenta (site B) & 94 & 6 & & 16 & 84 \\
Umbilical cord & 95 & 5 & & 30 & 70 \\
\hline
\end{tabular}

Samples of placenta were taken from two different regions, A and $\mathrm{B}$.

maternal blood. Interphase FISH analysis of over 180 nuclei in the TCC lavage sample showed the presence of two populations of cells: the first with two $\mathrm{X}$ and one $\mathrm{Y}$ chromosome signals, the second with one $\mathrm{X}$ and two Y signals. All 222 cells examined in the cervical mucus sample (including 10 squamous cells of maternal origin) contained two $\mathrm{X}$ and one $\mathrm{Y}$ signals. FISH tests carried out on umbilical cord and placental tissue from both twins showed that the two cell populations were present in all fetal samples examined, but at differing ratios (table 1). Placental and umbilical cord cells from twin A showed a predominant cell population with two $\mathrm{X}$ and one $Y$ signal; in twin $B$ the majority of the nuclei contained one $\mathrm{X}$ and two $\mathrm{Y}$ signals and the minority two $\mathrm{X}$ and one $\mathrm{Y}$ signals.

All maternal peripheral blood cells tested by interphase FISH showed two chromosome X and one $\mathrm{Y}$ signals. This blood was cultured and conventional cytogenetic analysis of chromosomes in metaphase showed the presence of a $15 \mathrm{p} ; \mathrm{Yq}$ translocation and thus a maternal karyotype of $46, \mathrm{XX}, \mathrm{t}(\mathrm{Y} ; 15)$ (qh;pter). These findings suggest that both fetuses were chimeras with different ratios of $\mathrm{XX}+\mathrm{Yqh}$ and $\mathrm{XY}+\mathrm{Yqh}$ cells, probably as a result of early interchange of embryonic cells.

\section{CASE 5}

In case 5, transcervical CVS performed 10 weeks 4 days after the last menstrual period showed a fetal karyotype of $47, \mathrm{XYY}$. Before TOP at 16 weeks 6 days, a suction aspiration TCC sample was obtained. FISH with X and Y specific probes performed on placental tissue obtained after TOP showed $95 \%$ of the 450 cells scored to be $47, \mathrm{XYY}$ and $5 \%$ to be $46, \mathrm{XY}$. Using an inverted microscope a clump of cells with the morphological characteristics of a syncitiotrophoblastic or cytotrophoblastic cellular element was isolated from the TCC aspiration sample. When tested with the same FISH assay, 50 of the 62 cells in this isolated clump were shown to contain one $\mathrm{X}$ and two $\mathrm{Y}$ chromosomes and thus to be of fetal origin. The remaining 12 cells had two $\mathrm{X}$ chromosomes and were therefore of maternal origin. No fetal cells were found using FISH in the remainder of the TCC sample despite examining over 400 nuclei; however, PCR using primers specific for the amelogenin region of the sex chromosomes performed on DNA extracted from the whole TCC sample showed the presence of Y specific DNA.

\section{Discussion}

Cells of fetal origin were successfully recovered from the TCC samples obtained in each of these five cases. In three cases TCC sampling was performed before any invasive procedure, confirming the natural presence of trophoblastic cellular elements in the endocervical canal of pregnant women. ${ }^{1-6}$ Fetal cells were observed in both aspiration and lavage samples obtained from those women undergoing both procedures.

The same FISH procedure for the detection of trisomy 21 , as performed in case 2 , was carried out on 12 pregnancies also at risk of chromosomal abnormalities without previous knowledge of the karyotype of the fetus. No cells with three chromosomes 21 were observed in any of these cases. Subsequent cultures of placental tissue confirmed that all fetuses were normal.

In case 4 , the presence of two populations of cells in fetal umbilical cord and placental tissues collected from each twin argues against the possibility of transfer of cells through anastomotic vessels across the placentae. If that were the case, chimerism would be limited only to the blood cells. The detection of constant but dissimilar ratios of two populations of cells in umbilical cord tissue as well as placenta in both fetuses suggests a possible exchange of cells at a very early stage of embryogenesis probably at the peri-implantation period. This particular time is suggested by the position of two placentae which appeared to be separated at the time of termination of pregnancy. It is also of interest that the diagnosis of a maternal translocation of $\mathrm{Y}$ chromosome heterochromatic material was achieved as a result of TCC sample analysis.

The present findings confirm the possibility of using TCC samples for the prenatal diagnoses of chromosomal abnormalities in the first trimester of pregnancy. We have also shown that by a simple micromanipulation procedure it is possible to isolate cells free from maternal contaminants. This offers the possibility of performing tests for the prenatal diagnosis of single gene disorders using clumps of fetal cells isolated from TCC samples. Work is now in progress to improve further the methods for the collection of TCC samples and also develop new approaches for the isolation of fetal cells.

We thank Joyce Harper for help in establishing the technique of FISH with directly labelled probes. Jon Sherlock is supported by FISH with directly labelled probes. Jon Sherlock is supported by wealth scholar, and Matteo Adinolfi is supported by the Dunhill Foundation. Cytogenetic analyses in cases 1,4 , and 5 were performed by staff of the University College London Hospital, Clinical Cytogenetics Unit, Galton Laboratory. The FISH procedure in case 1 was performed by Angela Davies.

1 Adinolfi M, Sherlock J, Tutschek B, Halder A, Delhanty J, Adinolf $M$, Sherlock $J$, Tutschek $B$, Halder A, Delhanty $J$ Rodeck C. Detection of fetal cells in transcervical samples and prenatal diagnosis of chro

Adinoli M, Davies A, Sharif S, Soothill P, Rodeck C. Adinolfi M, Davies A, Sharif S, Soothill P, Rodeck C.
Detection of trisomy 18 and Y-derived sequences in fetal Detection of trisomy 18 and Y-derived sequences in fetal
nucleated cells obtained by transcervical flushing. Lancet 1993;342:403-4.

3 Griffith-Jones MD, Miller D, Lilford RJ, Scott J, Bulmer J Detection of fetal DNA in trans-cervical swabs from the first trimester of pregnancies by gene amplification: a new route to prenatal diagnosis? Br f Obstet Gynaecol 1992;99: 508-11.

4 Adinolfi M, Sherlock J, Kemp T, et al. Prenatal detection of fetal RhD DNA sequences in transcervical samples. Lance 1995;345:318-19. 
5 Rodeck C, Tutschek B, Kingdom J, Sherlock J, Adinolfi $M$ Methods for the collection of transcervical samples during the first trimester of gestation. Prenat Diagn 1995;15:933 43.

6 Tutschek B, Sherlock J, Halder A, Delhanty J, Rodeck C Adinolfi $M$. Isolation of fetal cells from transcervical samples by micromanipulation: diagnosis of fetal aneuploidy and molecular confirmation of fetal origin. Prenat Diagn 1995;15:951-61.

7 Harper JC, Coonen E, Ramaekers FCS, et al. Identification of the sex of human preimplantation embryos in two hours using an improved spreading method and fluorescent in situ hybridisatic Reprod 1994;9:721
8 Davies AF, Barber $\mathrm{L}$ Murer-Orlando $\mathrm{M}$, Bobrow $\mathrm{M}$, Adinolfi M. FISH detection of trisomy 21 in interphase by contigs. F Med Genet 1994;31:679-85.

9 Mansfield ES. Diagnosis of Down syndrome and other aneuploidies using quantitative polymerase chain reaction and small tandem repeat polymorphisms. Hum Mol Genet 1993;2:43-50.

10 Pertl B, Yau SC, Sherlock J, Davies AF, Mathew CG, Adinolfi M. Rapid molecular method for prenatal detection of Down syndrome. Lancet 1995;343:1 197-8.

11 Nakahori Y, Takenaka O, Nakagome Y. A human X-Y homologous region encodes "amelogenin". Genomics 1991; 9:264-9. 